Lep. Rev. (1967) 38, 3, 139-148

\title{
Leprosy Field Logistics
}

\author{
Dr. M. J. MALLAC \\ Geneva, Switzerland
}

\section{INTRODUCTION}

It is no novelty to postulate that reports in general do actualise an accumulation of data, remarks and idiosyncrasies, rather than convey a uniformity of breadth and depth as regards the true dimensions of the leprosy problem in the field. Whereas this is almost unavoidable, yet it is also a truism to add that both the interest and value of a given system of reporting is directly proportional to the very way it is presented, to the very lucidity of its informations.

Although there are concerted views purporting to the whole magnitude of leprosy field work, no unifying system of reporting seems to enhance it so far, stock data not reflecting all the aspects of the picture since the endemicity of the disease varies from pocket to pocket and from belt to belt throughout the country. Besides, it would also be agreed that, from the point of view of epidemiology and control, the more minute the geographical breakdown, the clearer the nature of the problem, the firmer one's grasp over it.

With this in mind, the writer presents here an approach which, from want of a better term, bears the name of Leprosy Field Logistics as it embodies a fresh attempt at the national or mass campaign level and which, albeit not meant to replace field reports per se, nevertheless cuts through their variety and bulk in a direct, functional yet visual manner, aiming at the same time at a synthetic yet constructive evaluation of the problem on a yearly basis.

In effect, there is more in leprosy field work than the mere reporting of the total number of registered and treated patients per clinical type, sex and age group over a given period of time. There is more than the sorting out of patients within the demands of regularity of treatment. What are, for instance, the manpower and case-coverage? The work-load and expected case-load? The remaining coverage that can be reasonably expected from the present manpower? What is the overall balance for coverage? The full practical implications of case-finding, case-management and surveys?

\section{COMPONENTS OF FIELD LOGISTICS}

These have been worked out and based districtwise by the writer whilst on a recent wHO consultantship in Andhra Pradesh, India. In such a huge country-with its states, districts, taluks and blocks in that order-Leprosy Field Logistics could apply, for instance, state-wise at the National Leprosy Control Work; districtwise at the state level and, if necessary, taluk or block-wise at the periphery. Even for countries with much lesser densities of population, the writer advocates the division of field operations into a given number of zones to fit in the Leprosy Field Logistics whose basic components entail:-

\section{Organization and Communications Supervision and Co-ordination Manpower and Case-Coverage Case-Finding Surveys}

Each component, with the exception of the first one, shows on the left hand-side a map of the area involved (in this case the state of Andhra Pradesh); a central table with the relevant statistical informations district-wise and where the use of 2 colours like red and green is highly desirable for attracting one's immediate attention to the very weak and weak aspects of the statistics respectively; on the right hand-side, finally, the pertinent remarks cut down to a functional minimum under: (i) Present Picture (brief summary of the main statistical infor- 
mations); (ii) The Problem (implying the gaps to be filled), and (iii) Achievements (during the year).

ORGANIZATION ANI COMMUNICATIONS

These indicate the distribution, type and number of the various anti-leprosy units at the periphery; their relationship to the centre; the staff position; the expected work-load and case-load respectively.

\section{SUPERVISION ANI) CO-ORIINATION}

These show the general pattern of the state per district per zone; the area and population involved; the breakdown of all anti-leprosy units per district per zone.

\section{MANPOWER ANI CASE-COVERAGE}

Here, one has to reckon with the district population (DP), the population covered by all the anti-leprosy units (PC) - both Government and the Voluntary Agencies-and the percentage coverage involved. This is followed by: the present estimated cases per the Prevalence Rate of each district (EC); the number of registered ( $\mathrm{RC}$ ) and treated cases (TC); the attendance rate $(\mathrm{AR})$ and the amount of uncovered cases (UC). With the known manpower (MP) and the expected case-load (CL) at hand, one is in a measure to work out the approximate expected number of new cases (ENC) through the aforesaid manpower and the overall balance for coverage (BC).

\section{CASE-FINDING}

Care is taken to sort out the way patients are found, i.e., whether they report on their ownvoluntarily- $(\mathrm{V})$ or are detected through contact-tracing (CT), school surveys (SS), upon notification $(\mathbf{N})$ or through other sources (OS).

\section{CASE-MANAGEMENT}

This is the bigger component of the Leprosy Field Logistics, unavoidably so. One would like to know the number of yearly new cases (YNC) and thus ascertain the Incidence Rate of the disease. Apart from the usual sex distribution and the various age groups (giving us the ratio male to female and the Child Rate), it is advisable to record the emigration rate (ER) per district. This is followed by the percentage of 'open' cases (OC), the difference of which indicating the percentage of 'closed' ones. It is also advisable to include the following rates pertaining to: relapse $(R R)$, reaction $(L R)-$ of the lepromatous variety, disability (DyR), follow-up (FR) and death (DhR) as these are part and parcel of Leprosy Field Logistics. This section ends with the number of sign-free patients (SF) and those 'out of control' (OOC) during the year.

\section{SURVEYS}

Contact Survey: this shows the estimated number of contacts district-wise (EC) (in India, one has to reckon with an average of 5 members in the family). Of the total number examined throughout the year (TE) the leprosy rate $(\mathrm{Ly} R)$ can be determined as well as the balance for coverage (BC).

School Survey: indicates the total number of schools district-wise (TS), the number surveyed (NS), the pupil population (PP), the number examined (NE). The leprosy rate (LyR) can be worked out accordingly as well as the balance for survey (BS) and for examination (BE).

Mass Survey: if this cannot be done once every 5 years or so during the course of the mass campaign - as it is time-consumin $\because$ expensive and limited, at the best of times, to about $70 \%$ of the population-sampling surveys would be indicated, both with the population involved (PI), the population surveyed (PS), the leprosy rate in question (LyR) and the balance for survey (BS).

There are 2 more components of the Leprosy Field Logistics which, although not included in this series, are worth considering:-

Budget: this can be worked out per antileprosy unit per district per zone so as to have a comparative idea of the per capita cost (PCC), quite an important item in a mass campaign. 
In effect, if the per capita cost is too high in relationship to the 'output' of a particular anti-leprosy unit, this would indicate either a lesser Prevalence Rate in the area than was thought or sheer inefficiency on the part of the workers. Evidence in favour of the former would lead one to cut down the staff or close down that particular anti-leprosy unit and integrate it with the general health services of the area.

Extension Programme: this is also an important item which ensures continuity of field work until full control of the spread of the disease is achieved. As part and parcel of the Leprosy Field Logistics it would, as a function of the above, show the proposed increase in the antileprosy units per district per zone, translated into the corresponding increase in manpower and the additional case-coverage.

\section{CONCLUSIONS}

Leprosy Field Logistics would appear to be the answer to the further strengthening of field activities since, owing to their respective components, the whole picture emerges; its latitude can be seen at a glance; its importance can be readily grasped. They may, furthermore, give the control measures a new direction, and probably a new structure fitted to the increasing demands of field work. 


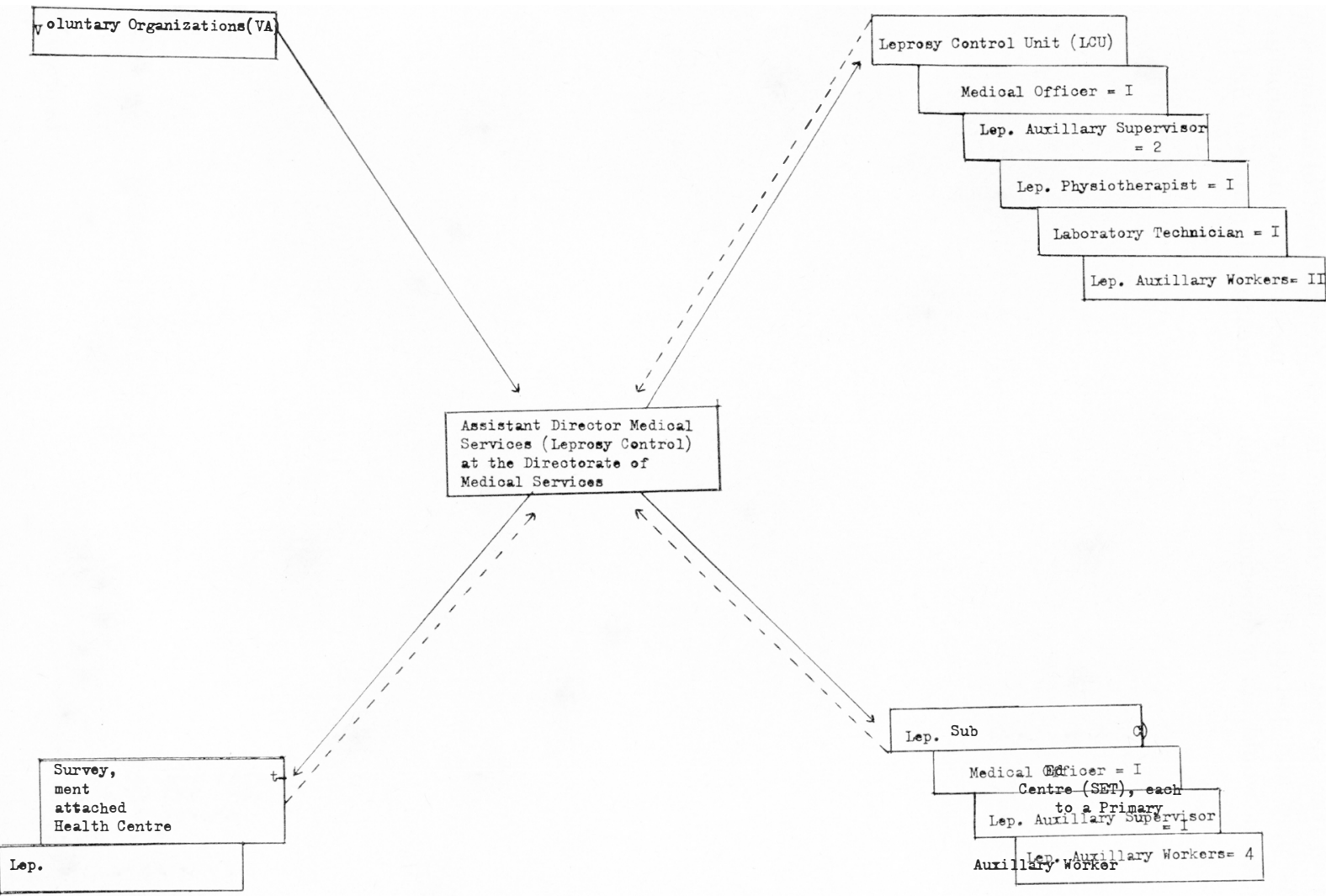

PRESENT PICTURE:

Iiaison from periphery: through Divisional Leprosy

a Zone comprising 4 districts.

No. of Digigional Lop. Superintendents $=3$

No.

No. of Ieg-Auxillary Supervisors $=20$

No. Lep. Auxillary Horkers

Work-load $=25-35000$ population per above worker

Case-10ad $=$ an expeoted 4-500 patient worker 
SUPERVISION \& CO-ORDINATICN

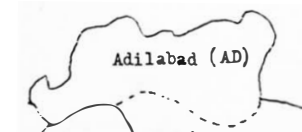

(IFD) Karianazar (KR) ).....
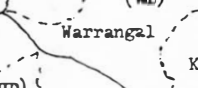

(MV) Méderabad $^{2}$

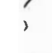

$\sum^{\text {Hahat }}$$$
2
$$$$
\ldots \ldots, \ldots(\mathrm{CR})
$$

( $R$

…-...

it apur i Cudd apah

$\rightarrow(\mathrm{A})^{-}-\mathrm{i}_{1}(\mathrm{CH})$

(CR)

Chittoor

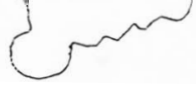

- 2otal bounciary

... District boundary

1. I06 286 sq. miles

2lation: 39 aidlitios

of Zones: 5

of Districts: 20

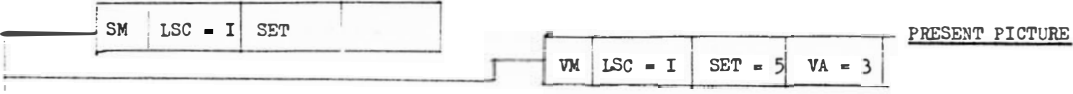

Totel No. of LCUs: 2

Total No. of LSCs: I6
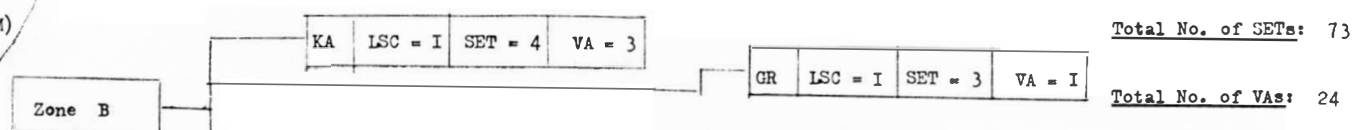

Srikakulam visakhapatnam Zone

East (VM)

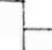

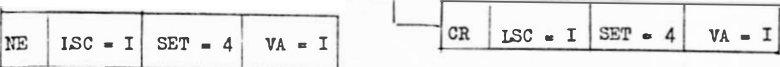

Grand Total of anti-leprosy units: II5

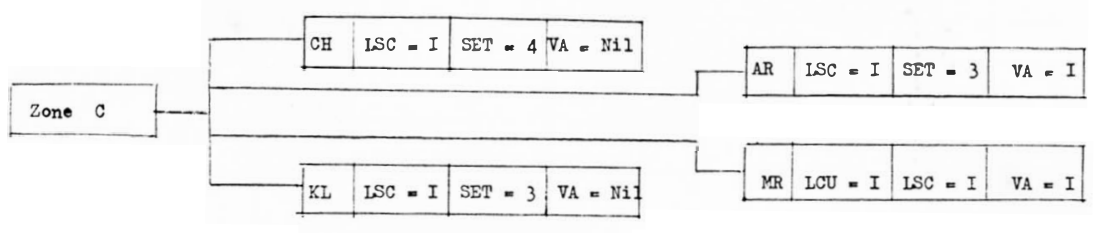

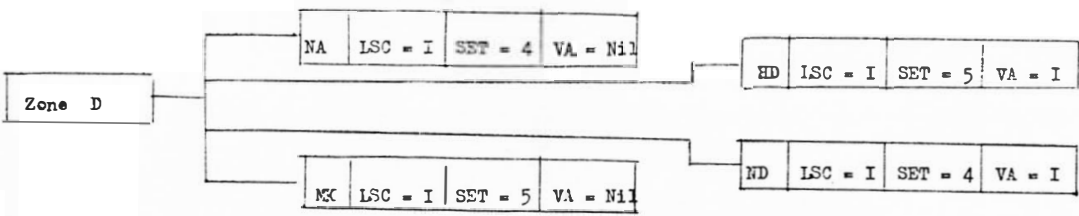

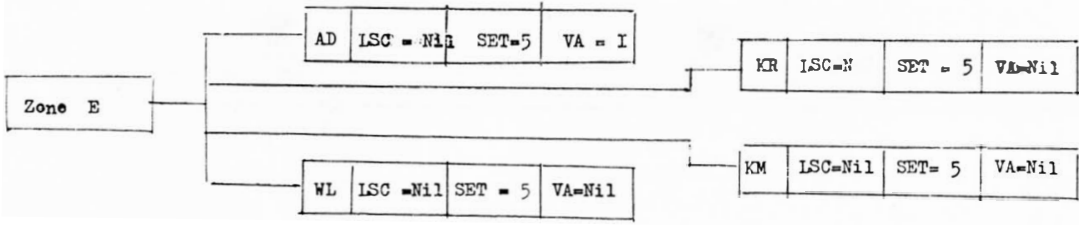




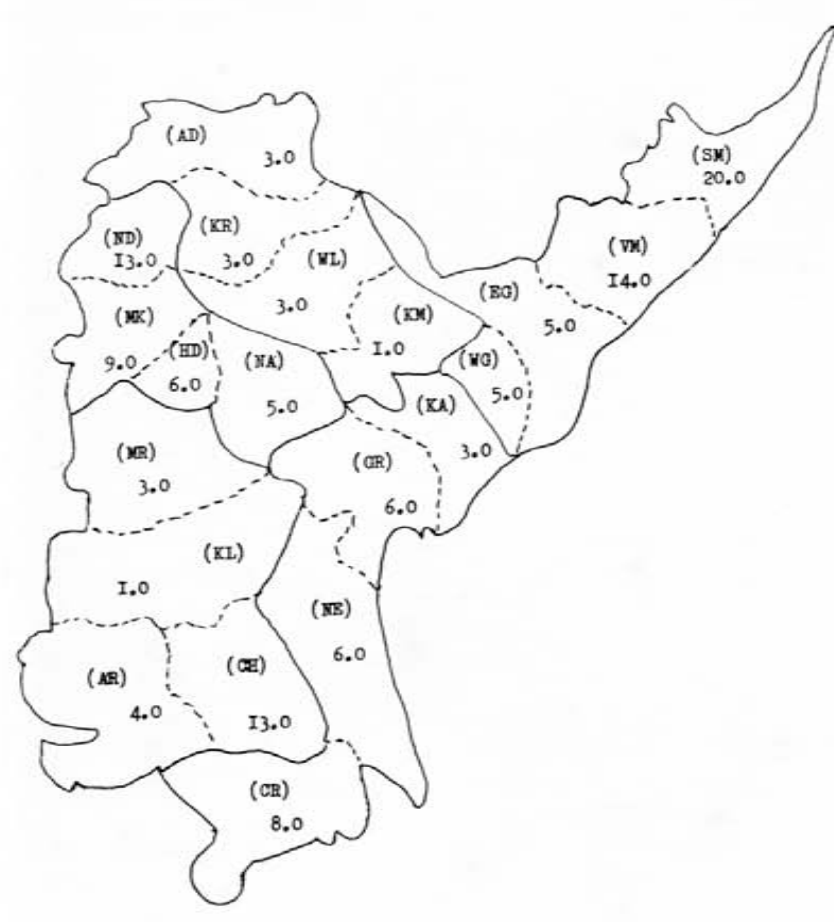

Present Prevalenoe Rate of Leprosy in mille per distriot per Zone

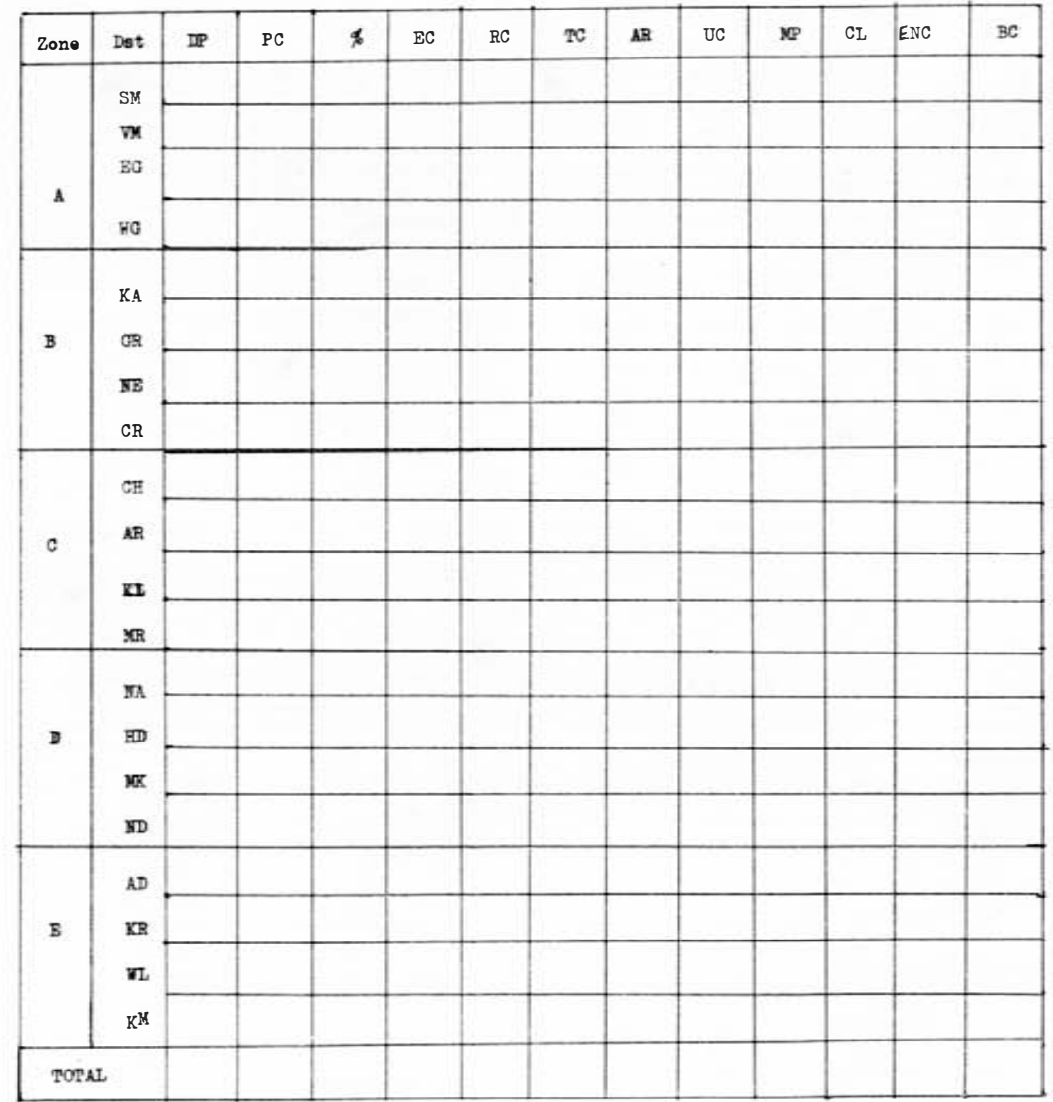

TEEP PROBL

ACHIEVEMENTS 

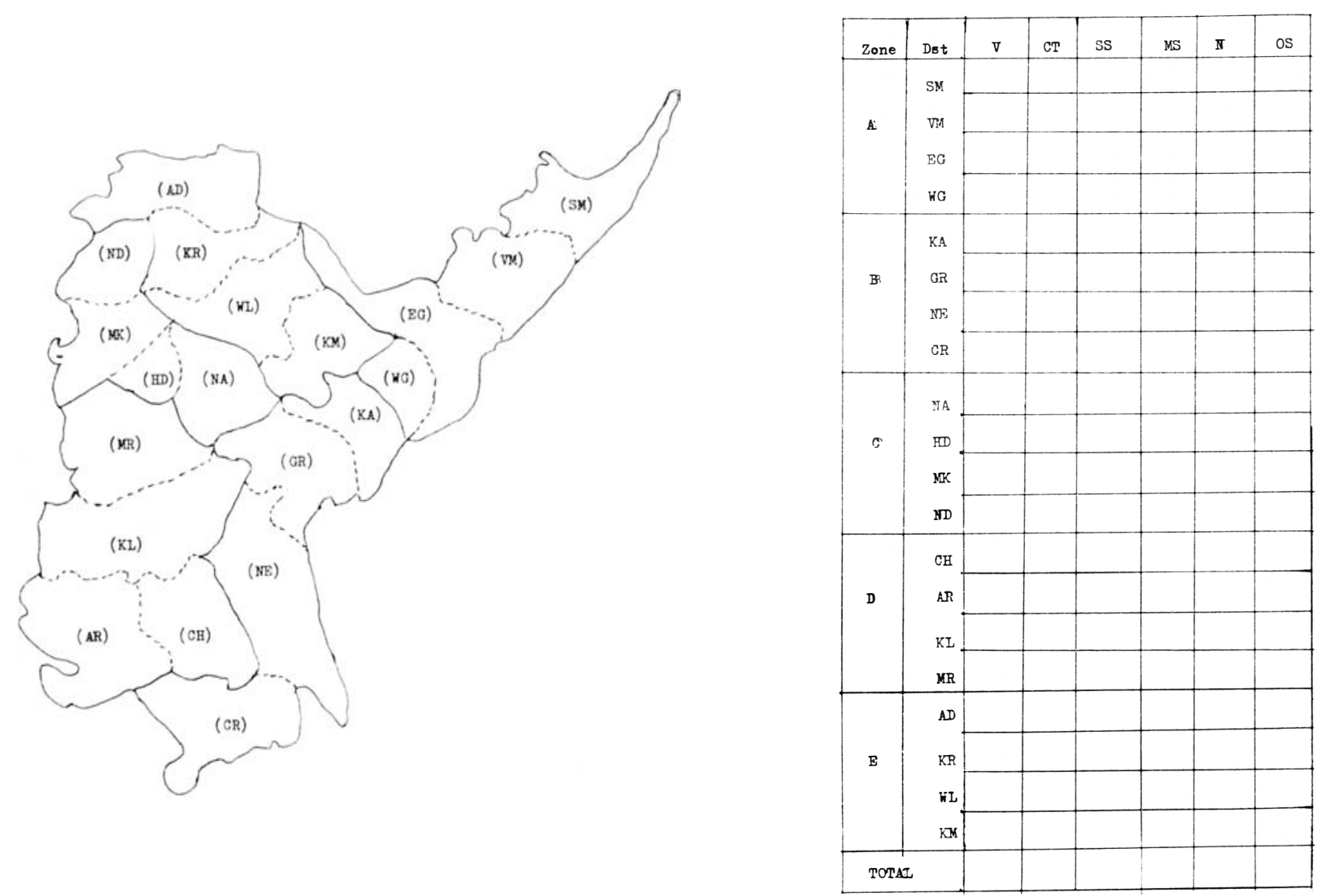

TES PROBIDM

-ACHIEVEREATSS 


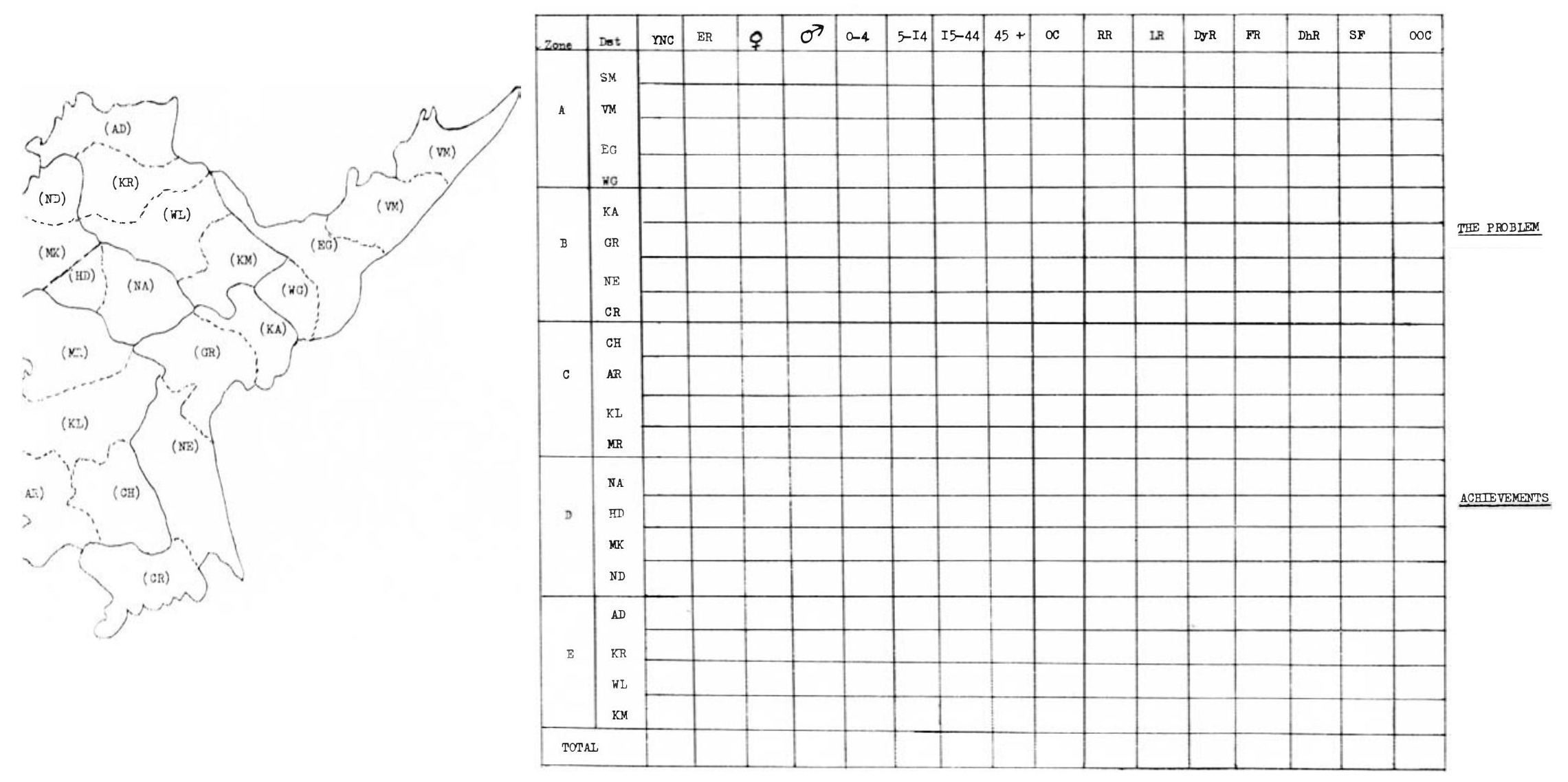




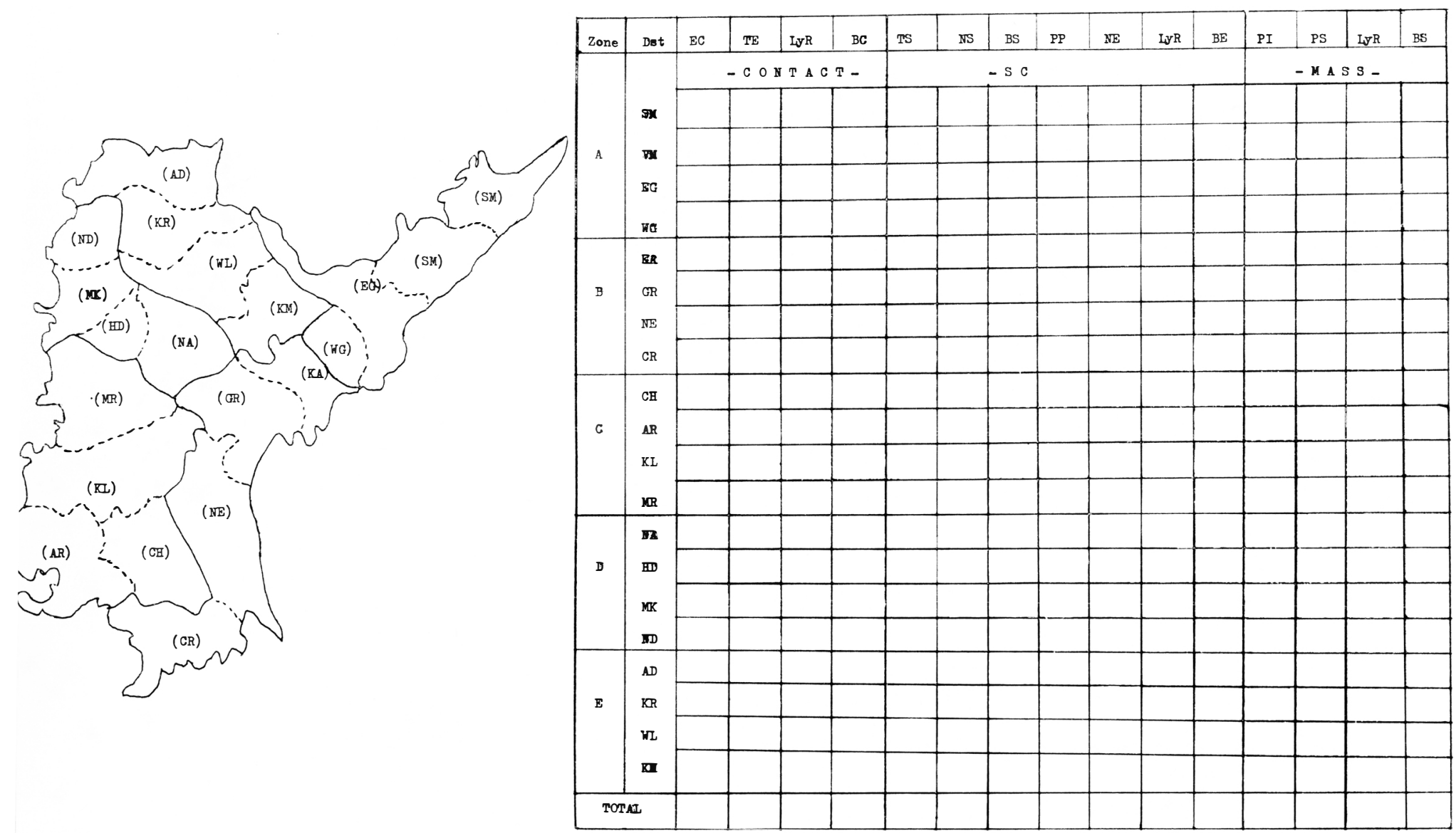

